\title{
Analysis of Factor Validity of the Support Intensity Scale on Bos- nian-Herzegovinian Sample
}

\author{
Alma Dizdarevic', Zulfo Ahmetovic', Daniel Malec'2, Amila Mujezinovic', \\ Melika Ahmetovic ${ }^{3}$, Fata Zilic', and Senad Mehmedinovic ${ }^{1}$ \\ 'Faculty of Education and Rehabilitation, University of Tuzla, Univerzitetska 1, Tuzla, Bosnia and Herzegovina \\ 2 Faculty of Education, University of Sarajevo, Skenderija 72, Sarajevo, Bosnia and Herzegovina \\ ${ }^{3}$ Department of Psychology Ludwig-Maximilians, University Munich, Germany
}

ABSTRACT

Since the development of the original Support Intensity Scale-Adult Version (SIS-A) and the Support Intensity Scale-Child Version (SIS-C), the interest in supporting people with intellectual disabilities (ID) has changed. Resource allocation, better quality of resource utilization in the rehabilitation process, the development of support systems, and redefining the roles of organizations that support people with ID are just some of the changes. The aim of this study was to determine the factor structure of the SIS-C conducted on a sample of Bosnian-Herzegovinian (B\&H) children (SISC B\&H). The study included 377 children ID in B\&H, aged 5-16. The data was analyzed with the SPSS 21 software (with the AMOS package). Exploratory factor analysis (EFA) was used to examine the factor structure of the SIS-C. Confirmatory factor analysis (CFA) was applied to determine the factor and constructive validity of SIS-C B\&H. The CFA results indicated a poor fit of both the theoretical and empirical models even after modifications were made. The EFA showed the opposite results. This could be explained by the fact that within the factor solutions obtained from the EFA, various aslope or orthogonal models, linear or hierarchical, can be constructed. Among these models, some exhibited good fit to the data. Thus, data from the current study could be used to generate new hypotheses and deliver more conclusive answers.

intellectual disability

support intensity

validity of children with ID/DD is essential for planning and developing appropriate support that can bridge the gap between people's current and desired life experiences (Thompson et al., 2009). The social-ecological model of disability (ICF; World Health Organization, 2001) which has been strongly advocated over the last two decades, has contributed significantly to changing the way in which people and children with ID/DD are evaluated.

Measuring the intensity of required support has been introduced at the international level through the first standardized, norm-referenced instrument, the Support Intensity Scale (SIS) for persons aged 16-64 (Thompson et al., 2004). A new psychological construct-the support needs - refers to the intensity of necessary support that a person needs in order to participate in daily life activities (Thompson et al., 2009). Support, in this case, is related to resources and strategies that can improve a person's functioning (Luckasson et al., 2002). These resources and strategies vary from person to person and depend on many factors. The construct of support needs is based on the premise that human

Corresponding author: Alma Dizdarević Faculty of Education and Rehabilitation, University of Tuzla, Bosnia and Herzegovina.E-mail: alma.dizdarevic@untz.ba 
functioning is influenced by the extent of congruence between individual capacities and the environments in which that person is expected to function (Thompson et al., 2014)

Numerous studies have confirmed that the purpose of the SIS is primarily to be used for individual support planning and resource allocation (Smith \& Fortune, 2008; Thompson et al., 2004; Weiss et al., 2009). It is further recommended that the SIS would be helpful to state systems in the decision-making process for education planning or resource allocation where the international interest in linking financial resources with the evaluation or assessment for support is enhanced (Kimmich et al., 2009; Schalock et al., 2008; Seo et al., 2016; Thompson et al., 2014; Van Loon, 2009).

From the time of the development of the original SIS to this day, this interest has changed from fairness to resource allocation through better quality resource utilization in the process of rehabilitation and development of support systems and through redefining the roles of organizations that support people with ID (Smith \& Fortune, 2008). Diagnosis alone is a poor predictor of the response to service, and a more holistic approach to needs assessment is needed (Mason \& Goddard, 2009; Salvador-Carulla et al., 2011; Snell et al., 2009). In the case of adults with intellectual disabilities, the Support Intensity Scale-Adult Version (SIS-A) has a very good empirical support for its validity, internal consistency, and test-retest reliability (Thompson et al., 2004).

The SIS-A was used in the development of the Support Intensity Scale-Children's Version (SIS-C) in order to better indicate the support needs of children with ID/DD and planning in an educational context. The SIS-C (Tassé \& Thompson, 2010) is designed to determine the profile and intensity of the support needs of children with ID aged 5-16. Originally developed by the American Association on Intellectual and Developmental Disabilities (AAIDD), the SIS-C is nowadays being translated into different languages in a manner parallel to the validation of the original version. Seven subscales have been included in this scale. The primary purpose of this scale is to address the shortage of standardized and validated measures of support needs for children, while considering the unique environment demands of childhood that include the demands of learning and participating in educational contexts (Thompson et al., 2014). The SIS- $\mathrm{C}$ would be useful for transition assessment and supports planning in younger children (Seo et al., 2016). Initial analysis of the SIS-C standardization sample suggests it is a valid and reliable tool for measuring support needs in children (Thompson et al., 2014).

Due to a lack of appropriate instruments for assessing the social adaptation of persons with ID, adaptation and standardization of Adaptive Behavior Scale (Nihara et al., 1969)-has been made in Bosnia and Herzegovina (Skala adaptivnog ponašanja, AAMD, Igrić \& Fulgosi-Masnjak, 1991). The AAMD assesses two areas-activities of everyday life and behavioural difficulties. The vast majority of experts in the field use this scale on a regular basis. However, the key differences in defining ID lie in the change in the concept of adaptive abilities as well as in the classification system based on the intensity of needed support, measured by a four-level scale of support instead of 10 areas of adaptive skills, as it was done before (Luckasson et al., 1992). The relation between support needs and adaptive behavior was a subject to research for many years. There is a consensus that these constructs are both related but ultimately different. There is also a reciprocity between support needs and adaptive behavior. Taking into consideration that persons with greater abilities need less support, it is expected that needed support decreases with age. It is for this reason that an instrument is needed in $\mathrm{B} \& \mathrm{H}$ to be used for assessment and creation of individual programs as well as for allocation of human and needed resources.

The aim of this study was to compare the factor structure of the SIS-C in a sample of B\&H children (SIS-C B\&H) with the factor structure of the original SIS-C version.

\section{METHODS}

\section{Participants}

The survey included 377 children with ID/DD in B\&H, aged 5-16. Children with ID/DD are educated in regular schools and in special schools. Inclusive education in primary schools is accessible for all categories of children with special needs, but only a small number of pupils with disabilities are officially registered. There is no official data on the exact number of children with ID/DD in B\&H. The participants were selected based on incidental sampling, with age (5-16 years old) and the presence of an intellectual disability (mild, moderate, severe, or profound) as the main inclusion criteria. Each participant had anamnestic data with information of presence and level of intellectual disabilities collected through previous psychological processing and assessment of standardized measuring instruments of the intelligence quotient (IQ).

A letter was sent to schools in $\mathrm{B} \& \mathrm{H}$ to recruit the required number of participants. After the initial contact, the schools which agreed to participate in the study received a formal letter and an informed consent form. These had to be voluntarily signed by the parents of all of the children. More than 20 schools, five special and 15 regular, participated in the study. After performing the evaluations and eliminating all the cases in which the data were missing, 377 evaluations were analysed.

Demographic information about all the participants was gathered through an initial questionnaire included on the cover page of the scale. All five special schools participated in the current study, with 521 pupils with ID, aged from 3 to 21 years. Of the entire number of included pupils with ID, 70\% attended special schools and 30\% attended regular schools, $62.9 \%$ were male, and $37.1 \%$ were female. The mean age of the total sample was 10.73 years $(S D=3.34)$. Table 1 provides additional child demographic information.

The participants were all born in $\mathrm{B} \& \mathrm{H}$ and had already been diagnosed by the Commission for the Categorization of Children with Special Needs as having mild (30.2\%), moderate (35.3\%), severe (32.4\%) and profound (2.1\%) intellectual disability. Most of the participants had the presence of other, concurrent conditions and disorders at the time of the data collection, similar to the original SIS-C sample. The 


\begin{tabular}{lcc}
\hline $\begin{array}{l}\text { TABLE 1. } \\
\text { Demographic Characteristics of the Sample }\end{array}$ \\
\hline \multicolumn{1}{c}{ Variable } & $n$ & $\%$ \\
\hline Gender & 237 & 62.9 \\
$\quad$ Male & 140 & 37.1 \\
$\quad$ Female & & \\
Adaptive behavior level & 114 & 30.2 \\
$\quad$ Mild & 133 & 35.3 \\
Moderate & 122 & 32.4 \\
Severe & 8 & 2.1 \\
Profound &
\end{tabular}

assessment was based on the judgment of other informants who knew the child well (teachers or staff directly involved in supporting the child). Specifically, 44 main informants were direct-care professionals (67.7\%) and 21 were teachers or staff directly involved in supporting the child (32.3\%).

\section{Procedure}

The SIS-C B\&H scale was translated, adapted, and pilot-tested. The scale was developed through a rigorous process of test adaptation and translation based on the approach given by Tassé and Thompson (2010). This approach included three boards, comprised of translators, bilingual experts, and potential users.

The SIS-C B\&H adopted the US process of data collection, where the scale was originally developed by a leading organization for defining ID in the world (Thompson et al., 2016). The agreement on the use of the AAIDD scale was signed as well. The data were stratified into two-year groups: 5-6, 7-8, 9-10, 11-12, 13-14, and 15-16 years old. Furthermore, the sample was stratified in age groups with respect to the level of adaptive functioning (mild, moderate, severe, and profound).

\section{Instruments}

This SIS-C scale has been developed according to the characteristics of the SIS-A (Thompson et al., 2004) and based on the socio-ecological concept of intellectual disability (Schalock et al., 2010). The aim of adapting this scale for children and adolescents (5-16 years old) was to allow for the assessment of individualized support needs at an early age, therefore facilitating the provision of individualized support and improving the quality of life.

The SIS-C B\&H translation is a standardized assessment and a valid means to measure the relative intensity of support needs of children with ID/DD between ages 5 to 16 .

The SIS-C B\&H consists of a series of items grouped into seven areas:

1. A-Life at home: 9 items

2. B-Community and neighborhood: 8 items

3. C-Participation in school: 9 items

4. D-School learning: 8 items

5. E-Health and safety: 9 items

6. F-Social skills: 9 items

7. G-Advocacy activities: 8 items.
The first part of SIS-C B\&H additionally includes general information about the child being evaluated: gender, chronological age, level of intelligence, level of adaptive behavior, origin, place of residence, etiology, combined difficulties in children, assistive technology.

The SIS-C B\&H was filled in by an interviewer. The interviewer who interviewed an individual child with intellectual disabilities collected information from at least two other informants. The interviews were conducted individually or with two or more informants at the time (group interview). Informants were persons who knew the child well (direct-care professionals, teachers, or staff directly involved in supporting the child).

Ratings reflected the level of support that a child needs to be successful in each of the observed activities. The concept of being successful is defined as engaging a child in all aspects of a particular activity in relation to contemporary school and social standards, which results in a maximum involvement (i.e., full participation) of the child in a given activity. In other words, successful engagement includes the level of achievement /involvement/participation in activities comparable with the child's typical peers.

Once the data collection process has been completed, the standard result for each area was further calculated and the standard composite score was designated as the Needed Support Index.

\section{Data Analysis}

The data was analyzed with the SPSS 21 software with the and AMOS package. Exploratory factor analysis (EFA) was used to examine the factor structure of the SIS-C B\&H. The principal components method has been used. In order to verify the factor solution of this measure in as many different ways as feasible, the orthogonal (Varimax) and slope rotations (Direct Oblimin rotation) of the factor frames were used. Confirmatory factor analysis (CFA) was applied to determine the factor and constructive validity of the SIS-C B\&H.

\section{RESULTS}

\section{Exploratory Factor Analysis}

The EFA was used to examine the factor structures of the SIS-C B\&H. Two criteria for the final number of extracted factors were used: (a) to have an Eigen-root greater than 1 and (b) that they can explain at least $50 \%$ of the total variance of all items. Based on the value of communalities, it was concluded that the extracted factors explained at least $58.3 \%$ of the variance of an entire manifest variable (particle C4-Arrival to school (including transport)-type of support) and a maximum of $92.6 \%$ variance of one whole variable (G8-Participation in educational decision-making). The first extracted factor alone explained $74.22 \%$ of the total variance, which was above the minimum acceptable level of $50 \%$. However, five factors had characteristic roots that were greater than 1 and these factors explained $83.59 \%$ of the total variance of all items. This indicates that the factor structure does not follow the theoretical or assumed structure with seven different factors. 
However, the high percentage of total variance explained confirms the satisfactory factor structure of the measure.

The Cattell scree-plot in Figure 1 shows the sudden flattening of the curve between the second and third factors. This means that the first factor contributes the most to the explanation of the total variance of all items. Other extracted factors, although having characteristic roots above 1 , did not significantly contribute to this percentage. The unrotated saturation matrix confirmed the results of previous considerations that all questionnaire items could be explained only by one general factor. However, rotations of the reference factors frames were carried out to determine how the items were grouped around the other extracted factors.

All the items in Scales G and D and the majority of items in Scale C were grouped around first factor. All items in Scale $\mathrm{E}$ and about half of the items in Scales B and F were grouped around other factors. All the items in Scale A were scattered and a minority of Scale C items were grouped around the third factor. Scale B items were grouped around the fourth factor. Finally, half of Scale F items were grouped around the fifth factor. This factor solution did not match the theoretical (sevenfactor) model. It also did not distinguish clear item clustering in such a way that one factor corresponds solely to the items of several scales. Items from Scales $\mathrm{G}$ and $\mathrm{D}$ were exclusively saturated with the first factor and Scale A items were exclusively saturated with the third factor.

An aslope rotation was carried out to see if a clearer factor solution could be obtained. Direct Oblimin rotation wasused.

Based on the results of the analysis shown in Table 2 and after the formal rotation, a similar grouping of items was obtained. Again, all the items in Scales G and D as well as the majority of items in Scale C were grouped together around the fifth factor. All Scale E items and about half the items in Scales B and F were grouped around the second factor. Almost all Scale A items (with the exception of A1) and a small number of Scale $\mathrm{C}$ items were grouped around the third factor. B-scale items are grouped together around the fourth factor. Finally, half of Scale F items were grouped around the fifth factor. This factor solution did not match the theoretical (seven-factor) model, and it also did not distinguish clear item clustering. Only the items in Scale G were

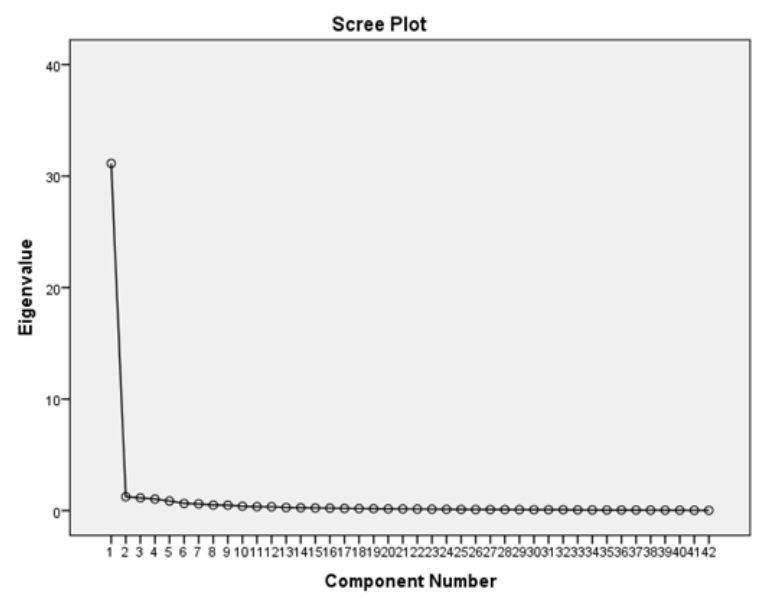

FIGURE 1.

Cattell scree plot. exclusively saturated with the first factor and items in Scale A-with the third factor.

The factor structure matrix shown in Table 3 merely follows the factor pattern matrix. The only difference was that in factor structure matrix, the total saturation is displayed regardless of the structure of these saturations. On the other hand, in the factor pattern matrix, only saturations are shown exclusively with the factor when the other particle correlating factors are removed or partialized.

\section{Confirmatory Factor Analysis}

Besides the EFA, a CFA was also carried out. The EFA considered only the factor structure of the SIS-C B\&H, without considering whether its structural model is in line with the theoretical model or if there is any other empirical model that would adequately explain its structure.

The CFA was applied to determine the factor and construct validity of the SIS-C B\&H. The CFA is a statistically stronger procedure than the EFA as it impartially tests how much a theoretically based model corresponds to empirical data. It is preferable that the model fits better to the covariance matrix in the actual data. The model is modified or rejected if the analysis determines poor fit.

In the data analysis, different criteria of model suitability were used, that is, the matching index of empirical data with the theoretical model, the chi-square test and its correction with regard to the number of degrees of freedom ( $\chi^{2} / \mathrm{df}$; relative $\left.\chi^{2}\right)$, and different comparative indexes (comparative fit index, CFI, normed fit index, NFI, root mean square error of approximation, RMSEA, goodness of fit index, GFI).

There are different opinions of psychometricians (according to Sram, 2014) on the values indicating structural quality. They agree that these values should not be less than the following: CFI and NFI greater than 0.90 (Bentler 1992), RMSEA values lower than 0.10 (Browne \& Cudeck, 1993), and GFI values equal to or greater than .85 (Cole 1987, Nunnely \& Bernstein 1994)

Therefore, the higher the CFI and NFI values and the lower the RMSEA values, the better the landing model. A good landing model is usually accepted if the value of a relative $\chi^{2}$ is less than 3.00 , but some researchers accept the value of 5.00 (Mueller, 1996). The coefficients in the interval of $0-1$ are the best fit indices, and the closer the indices are to 1 , the more the structure of the instrument fits with the assumed one.

The theoretical model without the modifications is shown in Figure 2. All indices of fit were not satisfactory for this model $\left(\chi^{2}\right.$ was significant and the term $\chi^{2} / \mathrm{df}$ was still above 5.00, RMSEA was greater than 0.08, AFS, NFI, and CFI were lower than 0.90 or 0.92 ). According to statistical calculations, significant and noticeable values of the index of modifications were taken to test if the model would be compatible with the theoretical one and if it fits the data well. According to these indices, correlated errors were taken into account (only for the generic model or assuming the presence of a methodological factor within the scale, but not between them).

After the modifications shown in Figure 3, the fit indices have been improved, but they were still not satisfactory. Only the term $\chi^{2} / \mathrm{df}$ indicated an adequate fitting of the model, but the values of all other indices indicated that the model was not functional and thus poorly fit. 
For this reason, a model following the rotated matrix from the previous EFA was used (see Figure 4).

However, the empirical model in Figure 4 showed a very poor fit to data, achieving index values lower than the theoretical model. In this case, modifications were made in the same way as with the theoretical model.

After the modifications presented in Figure 5, the empirical model showed improvements on some indices, but the values of several other were still poorer than for the theoretical model. It can be concluded that the empirical model achieved a poor fit.

The CFA results shown in Table 4 indicate a poor fit of both the theoretical and empirical models, even after modifications were made. For this reason, the models tested on this data have to be rejected. Nevertheless, this does not imply a weak factor structure of the measure. On the contrary, the EFA showed the opposite results. This could be explained by the fact that within the factor solutions obtained from the EFA, various aslope or orthogonal models, linear or hierarchical, can be constructed and some of the good fits could certainly be found. This could be considered a desideratum for future research and the existing data from this study can certainly be used to generate new hypothesis and deliver conclusive answers.

\section{DISCUSSION AND CONCLUSION}

The present study involved the exploratory and confirmatory analysis of factorial validity of the SIS-C questionnaire in a sample from $B \& H$. In response to a shift from a system-focused model to a personcentered model of support, Bossaert et al. (2009) conducted a survey examining the benefits of SIS-A for people with ID. Psychometric properties of the SIS-A, examined on a sample of 1303 people with different ID, and an analysis of the final factor failed to support the initially proposed six-step model within this sample.

Similar conclusions were reached in the current study. Results of the CFA indicated a poor fit of theoretical and empirical models of the SIS-C in a B\&H sample, even after modifications were done. However, this does not imply a weak factor structure of the measure. The results of the EFA indicated that the factorial structure does not follow the theoretical seven-factor structure. The measure itself has a satisfactory factor structure, however.

Child participants in the original SIS-C standardization sample and in the current sample showed large similarities in demographic characteristics, also with respect to gender and age. There was one significant difference in our sample, namely, there were too few participants $(2.1 \%)$ with profound disability, for they are barely represented in the education system in B\&H. These children are mostly at home and are not covered by any kind of support system. Therefore, it is very challenging to represent them in a sample. This could be the reason of the mismatch of the current study's data with the initially proposed seven-factor model.

Hagiwara et al. (2019) indicated that whenever a pair of respondents included a teacher or assistant, the support needs were scored lower than when the pair included a family member. In our research, the respondents were direct-care professionals and teachers or staff directly involved in supporting the child, which could also be considered a limitation of this study, deserving attention in replications.

Guillén Martín et al. (2017) performed a comparative analysis of the psychometric properties of the Spanish and Catalan versions of the SIS-C. Their results showed that both versions of the measure have sufficient internal consistency as measured via Cronbach's and a previous CFA performed with the SIS-A. Also, they detected several common patterns in both versions. In terms of internal consistency, both scales had a higher Cronbach's aon advocacy and community and neighborhood, and showed higher correlations in home life and lower in school learning.

The results obtained in our research are in accordance with results of previous studies conducted in this field, which speaks for the suitability of the SIS-C in assessing children with ID/DD. Verdugo et al. (2016) showed CFA results for a Spanish version of the SIS-C indicating that a unidimensional model was not sufficient to explain their data structure. Shogren et al. (2017) compared the reliability, validity, and measurement properties of the SIS-C in children with autism and ID and children with ID only. Their results suggest that the SIS-C is a reliable and valid a tool for both those groups. The results of multigroup CFAs showed that children with autism and ID tended to have a higher intensity of support needs in social activities across age, and children with ID only tended to have stronger correlations among support need domains measured on the SIS-C. The SIS-C is an innovative, international resource for evaluating the support needs of children and adolescents with ID from the socioecological perspective (Guillén Martín et al., 2017).

Research emphasizes the importance of assessment results for developing and validating meaningful ways of translating the information gained from support needs assessment to systems of support (Shogren et al., 2015). This information also plays a significant role in the development and implementation of individualized plans (Guillén Martín et al., 2017).

An analysis of the SIS-C B\&H's factor structure indicated that it does not follow the theoretical structure. Nevertheless, the high percentage of total variance confirms the satisfactory factor structure of the measure itself. The CFA indicated a poor fit of both the theoretical and empirical models. The findings suggest that the SIS-C B\&H can be used as a resource for allocation, assessment, and creation of individualized programs of support for children with ID/DD in B\&H. However, there is still there is for future research.

\section{ACKNOWLEDGEMENTS}

This study was supported in part by a grant from the B\&H Federal Ministry of Education and Science, (Grant Award No. 0539-2464-1/17). The opinions expressed do not necessarily reflect the position or policy of the B\&H Federal Ministry of Education and Science. 
TABLE 2.

Factor Pattern Matrix of the Supports Intensity Scale After Direct Oblimin Rotation

\begin{tabular}{|c|c|c|c|c|c|}
\hline \multirow{2}{*}{ Item } & \multicolumn{5}{|c|}{ Factor } \\
\hline & 1 & 2 & 3 & 4 & 5 \\
\hline A1. Completing household chores & & & 0.502 & 0.529 & \\
\hline A2. Eating & & & 0.671 & & \\
\hline A3. Washing and keeping self clean & & & 0.598 & & \\
\hline A4. Dressing & & & 0.596 & 0.502 & \\
\hline A5. Using the toilet & & & 0.592 & & \\
\hline A6. Sleeping and/or napping & & & 0.706 & & \\
\hline A7. Keeping track of personal belongings at home & & & 0.606 & & \\
\hline A8. Keeping self occupied during unstructured time (free time) at home & 0.553 & & 0.577 & & \\
\hline A9. Operating electronic devices & 0.508 & 0.525 & & & \\
\hline B1. Moving around the neighbourhood and community & & & & 0.732 & \\
\hline B2. Participating in leisure activities that require physical activity & & 0.533 & & & \\
\hline B3. Participating in leisure activities that do not require physical exertion & & 0.521 & & & \\
\hline B4. Using public services in one's community or neighborhood & & & & 0.677 & \\
\hline B5. Participating in community service and religious activities & & 0.543 & & 0.555 & \\
\hline B6. Shopping & & & & 0.678 & \\
\hline B7. Complying with basic community standards, rules, and/or laws & & 0.615 & & & \\
\hline $\begin{array}{l}\text { B8. Attending special events in the community or neighbourhood such as } \\
\text { cookouts/picnics,cultural festivals, music/art fairs, or holiday oriented events }\end{array}$ & & & & 0.513 & \\
\hline C1. Being included in general education classrooms & & & & 0.541 & \\
\hline $\begin{array}{l}\text { C2. Participating in activities in common school areas (e.g., playground, } \\
\text { hallways, cafeteria) }\end{array}$ & & & 0.586 & & \\
\hline \multicolumn{6}{|l|}{ C3. Participating in co-curricular activities } \\
\hline C4. Getting to school (includes transportation) & & & & 0.516 & \\
\hline C5. Moving around within the school and transitioning between activities & 0.502 & & 0.577 & & \\
\hline $\begin{array}{l}\text { C6. Participating in large-scale test taking activities required by state education } \\
\text { systems }\end{array}$ & 0.635 & & & & \\
\hline C7. Following classroom and school rules & & & 0.534 & & \\
\hline C8. Keeping track of personal belongings at school & 0.542 & & 0.535 & & \\
\hline C9. Keeping track of schedule at school & 0.599 & & & & \\
\hline D1. Accessing grade level curriculum content & 0.679 & & & & \\
\hline D2. Learning academic skills & 0.650 & & & & \\
\hline D3. Learning and using metacognitive strategies & 0.611 & & & & \\
\hline $\begin{array}{l}\text { D4. Completing academic tasks (e.g.time, quality, neatness, organizational } \\
\text { skills) }\end{array}$ & 0.693 & & & & \\
\hline D5. Learning how to use and using educational materials, technologies, and tools & 0.643 & & & & \\
\hline $\begin{array}{l}\text { D6. Learning how to use and using problem solving and self-regulation } \\
\text { strategies in the classroom }\end{array}$ & 0.723 & & & & \\
\hline D7. Participating in classroom level evaluations, such as tests & 0.706 & & & & \\
\hline D8. Accessing the health and physical education curricula & 0.656 & & & & \\
\hline D9. Completing homework assignments & 0.610 & & & & \\
\hline \multicolumn{6}{|l|}{$\begin{array}{l}\text { E1. Communicating health-related issues and medical problems, including } \\
\text { aches and pains }\end{array}$} \\
\hline E2. Maintaining physical fitness & & 0.576 & & & \\
\hline E3. Maintaining emotional well-being & & 0.537 & & & \\
\hline E4. Maintaining health and wellness & & 0.552 & & & \\
\hline $\begin{array}{l}\text { E5. Implementing routine first aid when experiencing minor injuries such as a } \\
\text { bloody nose }\end{array}$ & & 0.742 & & & \\
\hline E6. Responding in emergency situations & & 0.741 & & & \\
\hline E7. Protecting self from physical, verbal, and/or sexual abuse & & 0.679 & & & \\
\hline
\end{tabular}


TABLE 2.

Factor Pattern Matrix of the Supports Intensity Scale After Direct Oblimin Rotation (Cont.)

\begin{tabular}{|c|c|c|c|c|c|}
\hline \multirow{2}{*}{ Item } & \multicolumn{5}{|c|}{ Factor } \\
\hline & 1 & 2 & 3 & 4 & 5 \\
\hline E8 Avoiding health and safety hazards & & 0.617 & & & \\
\hline F1. Maintaining positive relationships with others & & & 0.500 & & \\
\hline F2. Respecting the rights of others & & 0.510 & & & \\
\hline F3. Maintaining conversation & & & & & 0.774 \\
\hline F4. Responding to and providing constructive criticism & & 0.587 & & & \\
\hline F5. Coping with changes in routines and/or transitions across social situations & & 0.581 & & & \\
\hline F6. Making and keeping friends & & 0.510 & & & 0.594 \\
\hline F7. Communicating with others in social situations & & & & & 0.765 \\
\hline F8. Respecting others personal space/property & & 0.522 & & & 0.558 \\
\hline F9. Protecting self from exploitation and bullying & & 0.543 & & & \\
\hline G1. Expressing preferences & 0.612 & & & & \\
\hline G2. Setting personal goals & 0.637 & & & & \\
\hline G3. Taking action and attaining goals & 0.670 & & & & \\
\hline G4. Making choices and decisions & 0.621 & & & & \\
\hline G5. Advocating for and assisting others & 0.635 & & & & \\
\hline G6. Learning and using self-advocacy skills & 0.650 & & & & \\
\hline G7. Communicating personal wants and needs & 0.564 & & & & \\
\hline G8. Participating in educational decision making & 0.677 & & & & \\
\hline $\begin{array}{l}\text { G9. Learning and using problem solving and self-regulation strategies in the } \\
\text { home and community }\end{array}$ & 0.657 & 0.516 & & & \\
\hline
\end{tabular}

Note. Saturation valuies less than 0.50 are not displayed.

TABLE 3.

Factor Structure Matrix of the Supports Intensity Scale After Direct Oblimin Rotation

\begin{tabular}{|c|c|c|c|c|c|}
\hline \multirow{2}{*}{ Item } & \multicolumn{5}{|c|}{ Factor } \\
\hline & 1 & 2 & 3 & 4 & 5 \\
\hline A1. Completing household chores & 0.819 & & 0.769 & -0.677 & -0.622 \\
\hline A2. Eating & 0.797 & & 0.738 & -0.636 & -0.782 \\
\hline A3. Washing and keeping self clean & 0.810 & & 0.748 & -0.556 & -0.704 \\
\hline A4. Dressing & 0.779 & & 0.759 & -0.636 & -0.703 \\
\hline A5. Using the toilet & 0.765 & & 0.731 & -0.625 & -0.699 \\
\hline A6. Sleeping and/or napping & 0.524 & & 0.530 & -0.452 & -0.783 \\
\hline A7. Keeping track of personal belongings at home & 0.838 & & 0.702 & -0.668 & -0.736 \\
\hline A8. Keeping self occupied during unstructured time (free time) at home & 0.884 & & 0.746 & -0.625 & -0.716 \\
\hline A9. Operating electronic devices & 0.787 & & 0.732 & -0.447 & -0.574 \\
\hline B1. Moving around the neighbourhood and community & 0.711 & 0.431 & 0.790 & -0.695 & -0.444 \\
\hline B2. Participating in leisure activities that require physical activity & 0.767 & & 0.878 & -0.573 & -0.619 \\
\hline B3. Participating in leisure activities that do not require physical exertion & 0.755 & & 0.821 & -0.629 & -0.611 \\
\hline B4. Using public services in one's community or neighborhood & 0.738 & & 0.859 & -0.603 & \\
\hline B5. Participating in community service and religious activities & 0.796 & & 0.909 & -0.633 & -0.433 \\
\hline B6. Shopping & 0.743 & & 0.878 & -0.614 & \\
\hline B7. Complying with basic community standards, rules, and/or laws & 0.802 & & 0.852 & -0.639 & -0.545 \\
\hline $\begin{array}{l}\text { B8. Attending special events in the community or neighbourhood such as } \\
\text { cookouts/picnics,cultural festivals, music/art fairs, or holiday oriented events }\end{array}$ & 0.793 & & 0.870 & -0.616 & -0.544 \\
\hline C1. Being included in general education classrooms & 0.762 & & 0.658 & -0.755 & -0.502 \\
\hline
\end{tabular}


TABLE 3.

Factor Structure Matrix of the Supports Intensity Scale After Direct Oblimin Rotation (Cont.)

\begin{tabular}{|c|c|c|c|c|c|}
\hline \multirow{2}{*}{ Item } & \multicolumn{5}{|c|}{ Factor } \\
\hline & 1 & 2 & 3 & 4 & 5 \\
\hline $\begin{array}{l}\text { C2. Participating in activities in common school areas (e.g., playground, } \\
\text { hallways, cafeteria) }\end{array}$ & 0.867 & & 0.776 & -0.655 & -0.725 \\
\hline C3. Participating in co-curricular activities & 0.850 & & 0.770 & -0.621 & -0.649 \\
\hline C4. Getting to school (includes transportation) & 0.697 & & 0.652 & -0.498 & \\
\hline C5. Moving around within the school and transitioning between activities & 0.861 & & 0.747 & -0.645 & -0.710 \\
\hline C6. Participating in large-scale test taking activities required by state education systems & 0.793 & & 0.678 & -0.504 & \\
\hline C7. Following classroom and school rules & 0.849 & & 0.738 & -0.682 & -0.687 \\
\hline C8. Keeping track of personal belongings at school & 0.874 & & 0.711 & -0.730 & -0.684 \\
\hline C9. Keeping track of schedule at school & 0.903 & & 0.768 & -0.661 & -0.612 \\
\hline D1. Accessing grade level curriculum content & 0.924 & & 0.741 & -0.619 & -0.563 \\
\hline D2. Learning academic skills & 0.931 & & 0.764 & -0.670 & -0.583 \\
\hline D3. Learning and using metacognitive strategies & 0.887 & & 0.786 & -0.646 & -0.443 \\
\hline D4. Completing academic tasks (e.g.,time, quality, neatness, organizational skills) & 0.941 & & 0.752 & -0.638 & -0.572 \\
\hline D5. Learning how to use and using educational materials, technologies, and tools & 0.928 & & 0.795 & -0.646 & -0.542 \\
\hline $\begin{array}{l}\text { D6. Learning how to use and using problem solving and self-regulation } \\
\text { strategies in the classroom }\end{array}$ & 0.949 & & 0.791 & -0.582 & -0.502 \\
\hline D7. Participating in classroom level evaluations, such as tests & 0.903 & & 0.763 & -0.540 & -0.425 \\
\hline D8. Accessing the health and physical education curricula & 0.919 & & 0.800 & -0.599 & -0.508 \\
\hline D9. Completing homework assignments & 0.899 & & 0.760 & -0.650 & -0.555 \\
\hline $\begin{array}{l}\text { E1. Communicating health-related issues and medical problems, including } \\
\text { aches and pains }\end{array}$ & 0.773 & & 0.819 & -0.659 & -0.607 \\
\hline E2. Maintaining physical fitness & 0.780 & & 0.863 & -0.541 & -0.636 \\
\hline E3. Maintaining emotional well-being & 0.854 & & 0.867 & -0.608 & -0.541 \\
\hline E4. Maintaining health and wellness & 0.861 & & 0.882 & -0.586 & -0.553 \\
\hline $\begin{array}{l}\text { E5. Implementing routine first aid when experiencing minor injuries such as a } \\
\text { bloody nose }\end{array}$ & 0.766 & & 0.855 & -0.524 & -0.481 \\
\hline E6. Responding in emergency situations & 0.784 & & 0.855 & -0.521 & -0.448 \\
\hline E7. Protecting self from physical, verbal, and/or sexual abuse & 0.751 & & 0.885 & -0.620 & -0.437 \\
\hline E8 Avoiding health and safety hazards & 0.767 & & 0.890 & -0.615 & -0.487 \\
\hline F1. Maintaining positive relationships with others & 0.816 & & 0.757 & -0.798 & -0.680 \\
\hline F2. Respecting the rights of others & 0.809 & & 0.762 & -0.785 & -0.647 \\
\hline F3. Maintaining conversation & 0.668 & & 0.603 & -0.939 & \\
\hline F4. Responding to and providing constructive criticism & 0.821 & & 0.826 & -0.784 & -0.497 \\
\hline F5. Coping with changes in routines and/or transitions across social situations & 0.834 & & 0.827 & -0.743 & -0.499 \\
\hline F6. Making and keeping friends & 0.803 & & 0.781 & -0.862 & -0.546 \\
\hline F7. Communicating with others in social situations & 0.672 & & 0.639 & -0.937 & \\
\hline F8. Respecting others personal space/property & 0.779 & & 0.769 & -0.827 & -0.582 \\
\hline F9. Protecting self from exploitation and bullying & 0.798 & & 0.832 & -0.728 & -0.434 \\
\hline G1. Expressing preferences & 0.873 & & 0.726 & -0.665 & -0.522 \\
\hline G2. Setting personal goals & 0.906 & & 0.773 & -0.728 & -0.443 \\
\hline G3. Taking action and attaining goals & 0.926 & & 0.793 & -0.626 & -0.508 \\
\hline G4. Making choices and decisions & 0.897 & & 0.763 & -0.737 & -0.460 \\
\hline G5. Advocating for and assisting others & 0.911 & & 0.763 & -0.765 & -0.476 \\
\hline G6. Learning and using self-advocacy skills & 0.931 & & 0.806 & -0.738 & -0.458 \\
\hline G7. Communicating personal wants and needs & 0.833 & & 0.696 & -0.687 & -0.503 \\
\hline G8. Participating in educational decision making & 0.937 & & 0.816 & -0.690 & -0.448 \\
\hline $\begin{array}{l}\text { G9. Learning and using problem solving and self-regulation strategies in the } \\
\text { home and community }\end{array}$ & 0.917 & & 0.819 & -0.653 & -0.424 \\
\hline
\end{tabular}

Note. Saturation valuies less than 0.420 are not displayed. 


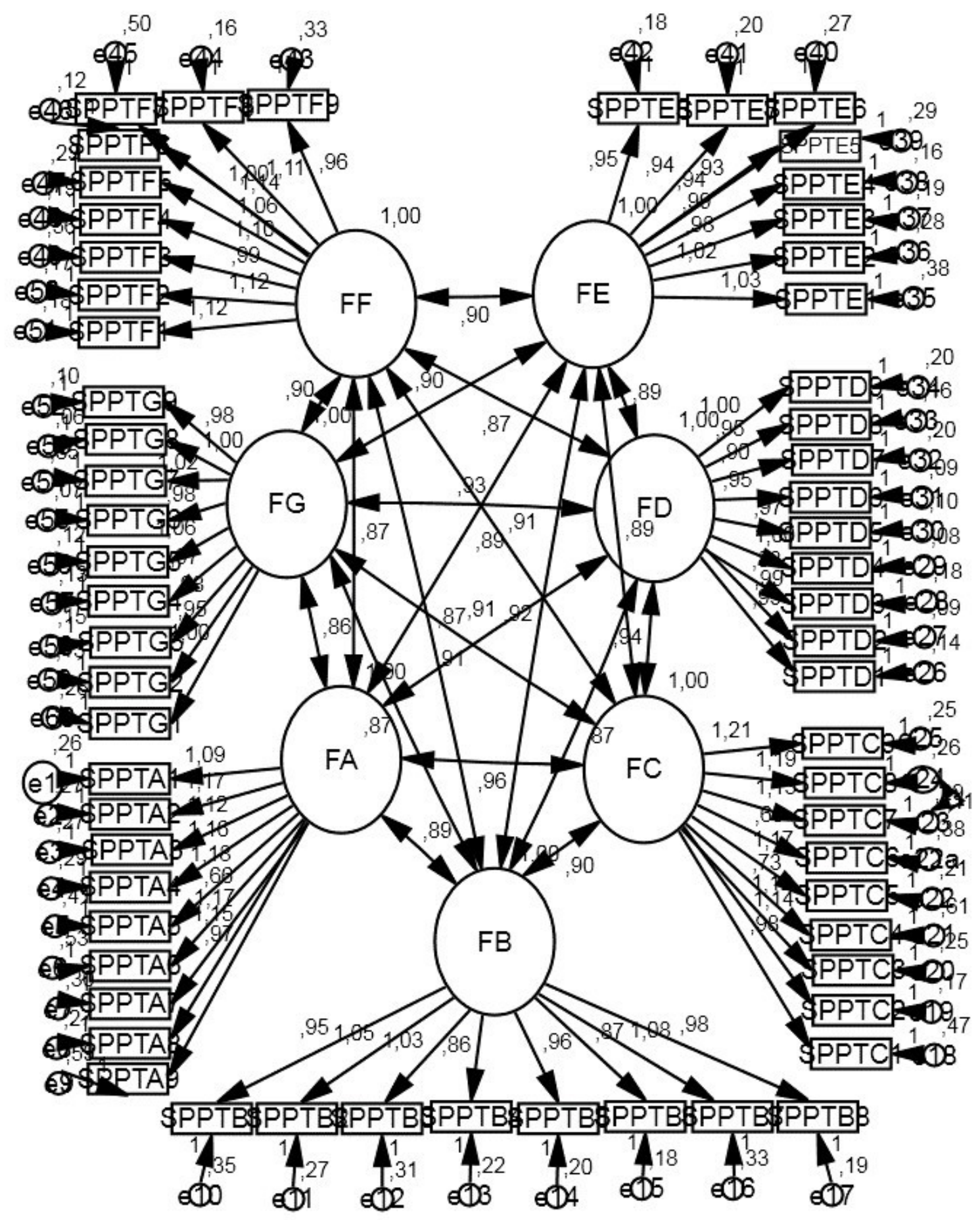

FIGURE 2.

Theoretical model. $\mathrm{FA}=$ latent factor related to $\mathrm{A}$ scale. $\mathrm{FB}=$ latent factor related to $\mathrm{B}$ scale. $\mathrm{FC}=$ latent factor related to $\mathrm{C}$ scale. $\mathrm{FD}=$ latent factor related to $D$ scale. $F E=$ latent factor related to $E$ scale. FF = latent factor related to $F$ scale. $F G=$ latent factor related to $G$ scale. PPTA = items related to SIS'A-Type of support subscale. PPTB = items related to SIS'B-Type of support subscale. PPTC = items related to SIS'C-Type of support subscale. PPTD = items related to SIS'D-Type of support subscale. PPTE = items related to SIS'E-Type of support subscale. PPTF = items related to SIS'F-Type of support subscale. PPTG = items related to SIS' G-Type of support subscale. $\mathrm{e}=$ error term variance or residual variance of an item (variance non attributable to the factors in the model). Two-ways arrow values = correlation between two factors. One-way arrow values = standardized regression coefficients (dependent variable are arrowed against and values represent how many units a dependent variable changes by one unit change of an independent variable). 


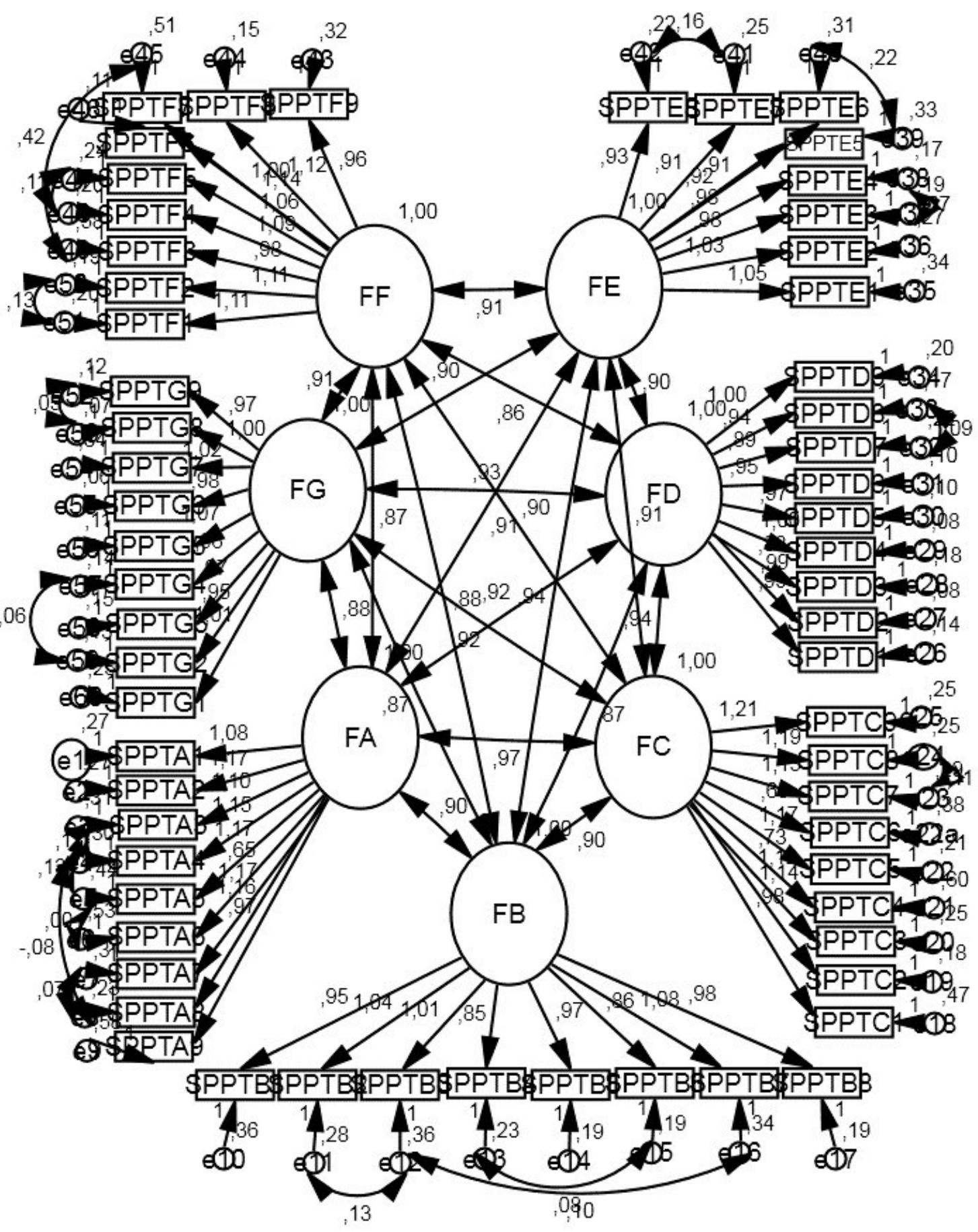

FIGURE 3.

Theoretical model. $\mathrm{FA}=$ latent factor related to $\mathrm{A}$ scale. $\mathrm{FB}=$ latent factor related to $\mathrm{B}$ scale. $\mathrm{FC}=$ latent factor related to $\mathrm{C}$ scale. $\mathrm{FD}=$ latent factor related to $\mathrm{D}$ scale. $\mathrm{FE}=$ latent factor related to $\mathrm{E}$ scale. $\mathrm{FF}=$ latent factor related to $\mathrm{F}$ scale. $\mathrm{FG}=$ latent factor related to $\mathrm{G}$ scale. PPTA = items related to SIS A-Type of support subscale. PPTB = items related to SIS' B-Type of support subscale. PPTC = items related to SIS' C-Type of support subscale. PPTD = items related to SIS'D-Type of support subscale. PPTE = items related to SIS'E-Type of support subscale. PPTF = items related to SIS'F-Type of support subscale. PPTG = items related to SIS'G-Type of support subscale. e = error term variance or residual variance of an item (variance non attributable to the factors in the model). Two-ways arrow values $=$ correlation between two factors or/and correlation between two error terms. One-way arrow values = standardized regression coefficients (dependent variable are arrowed against and values represent how many units a dependent variable changes by one unit change of an independent variable).. 


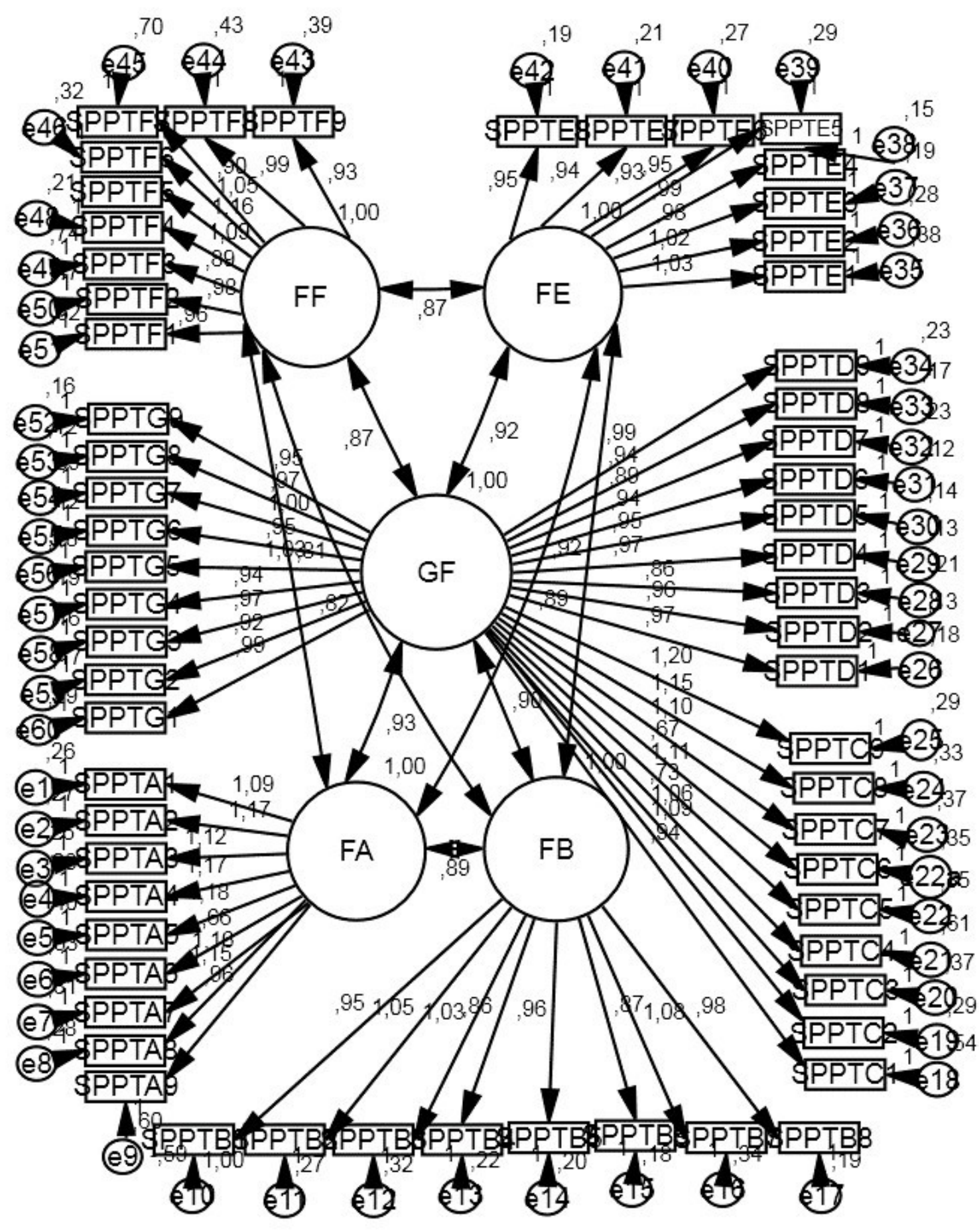

FIGURE 4.

Empirical model. GF = factor related to the added (combined) C-scale and G-scale. FA = latent factor related to A scale. FB = latent factor related to $B$ scale. FD = latent factor related to $D$ scale. FE = latent factor related to $E$ scale. FF = latent factor related to $F$ scale. PPTA = items related to SIS'A-Type of support subscale. PPTB = items related to SIS'B-Type of support subscale. PPTC = items related to SIS'C-Type of support subscale. PPTD = items related to SIS'D-Type of support subscale. PPTE = items related to SIS'E-Type of support subscale. PPTF = items related to SIS'F-Type of support subscale. PPTG = items related to SIS'G-Type of support subscale. e = error term varance or residual variance of an item (variance non attributable to the factors in the model). Two-ways arrow values $=$ correlation between two factors. One-way arrow values = standardized regression coefficients (dependent variable are arrowed against and values represent how many units a dependent variable changes by one unit change of an independent variable). 


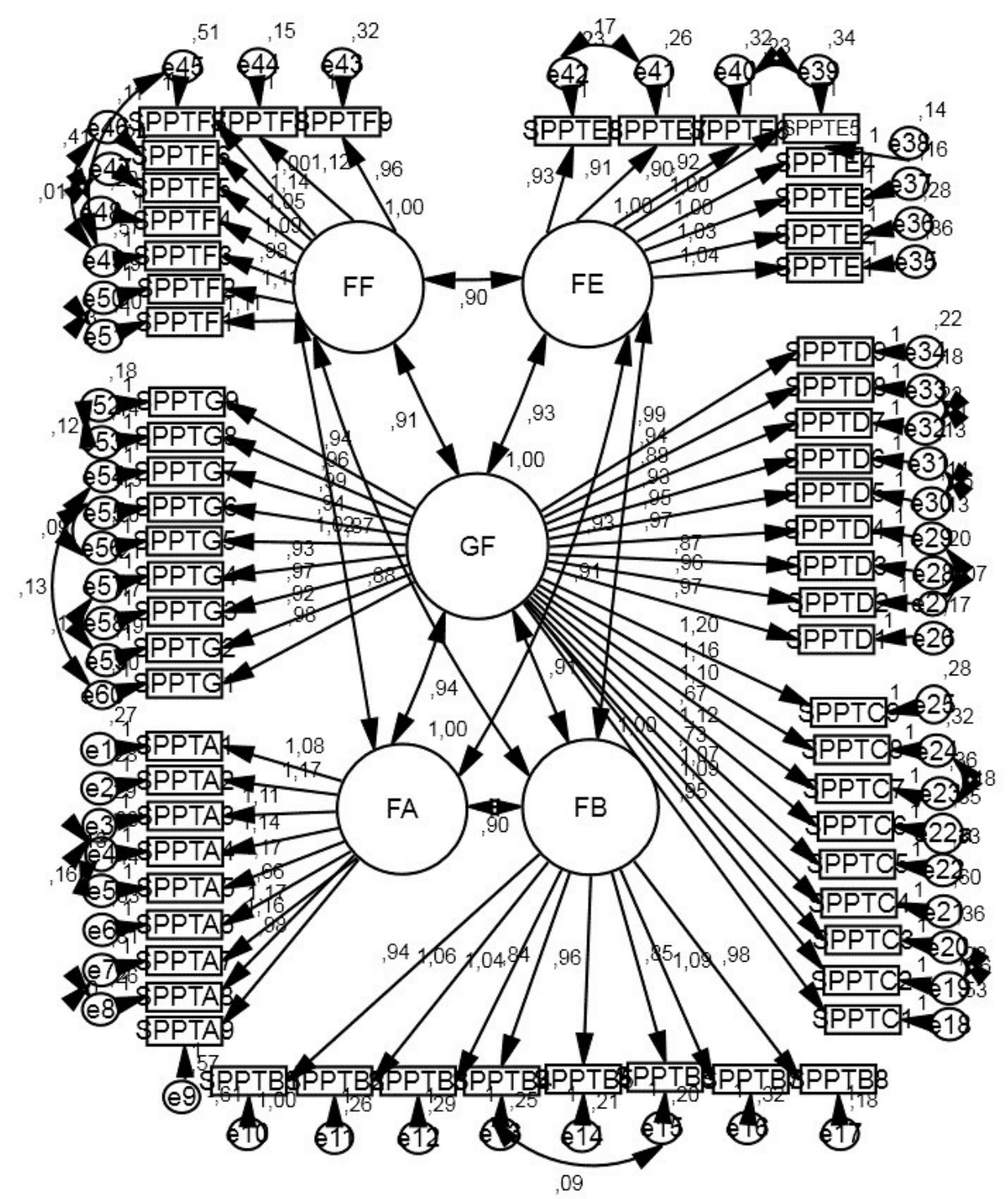

FIGURE 5.

Empirical model with modifications. GF = factor related to the added (combined) C-scale and G-scale. FA = latent factor related to A scale. $F B=$ latent factor related to $B$ scale. $F D=$ latent factor related to $D$ scale. $F E=$ latent factor related to $E$ scale. FF = latent factor related to F scale. PPTA = items related to SIS'A-Type of support subscale. PPTB = items related to SIS'B-Type of support subscale. PPTC = items related to SIS C-Type of support subscale. PPTD = tems related to SIS'D-Type of support subscale. PPTE $=$ items related to SIS'E-Type of support subscale. PPTF = items related to SIS'F-Type of support subscale. PPTG = items related to SIS'G-Type of support subscale. $\mathrm{e}=$ error term variance or residual variance of an item (variance not attributable to the factors in the model). Two-ways arrow values = correlation between two factors or/and between two error terms. One-way arrow values = standardized regression coefficients (dependent variable are arrowed against and values represent how many units a dependent variable changes by one unit change of an independent variable).

\begin{tabular}{|c|c|c|c|c|c|c|c|c|}
\hline \multicolumn{9}{|c|}{$\begin{array}{l}\text { TABLE } 4 . \\
\text { Indices of Fit for the Theoretical and Empirical Models }\end{array}$} \\
\hline Model & $\chi^{2}$ & $\mathrm{df}$ & $p$ & $\chi^{2} / \mathrm{df}$ & GFI & NFI & CFI & RMSEA \\
\hline Theoretical model & 10130.875 & 1747 & .00 & 5.799 & .480 & 0.774 & 0.805 & 0.113 \\
\hline $\begin{array}{l}\text { Theoretical model with implemented } \\
\text { modifications }\end{array}$ & 8387.733 & 1730 & .00 & 4.848 & .554 & 0.813 & 0.845 & 0.101 \\
\hline Empirical model & 13044.370 & 1760 & .00 & 7.412 & .390 & 0.709 & 0.737 & 0.131 \\
\hline $\begin{array}{l}\text { Empirical model with implemented } \\
\text { modifications }\end{array}$ & 9404.067 & 1740 & .00 & 5.405 & .521 & 0.790 & 0.822 & 0.108 \\
\hline
\end{tabular}

Note. $p \leq 0.05$ 


\section{REFERENCES}

Bentler, P. M. (1992). On the fit of models to covariances and methodology to the Bulletin. Psychological Bulletin, 112, 400404. doi: 10.1037/0033-2909.112.3.400 السلسلس

Bossaert, G., Kuppens, S., Buntinx, W., Molleman, C., Van Den Abeele. A., \& Maes, B. (2009). Usefulness of the Supports Intensity Scale (SIS) for persons with other than intellectual disabilities. Research In Developmental Disabilities, 30, 1306-

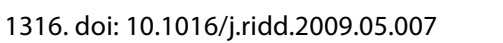

Browne, M. W., \& Cudeck, R. (1993). Alternative ways of assessing model fit. In: K. A. Bollen, \& J. S. Long (Eds.), Testing structural equation models (pp. 136-162). Sage.

Cole, D. A. (1987). Utility of confirmatory factor analysis in test validation research. Journal of Consulting and Clinical Psychology

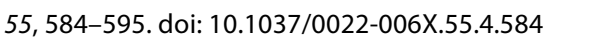

Igrić, Lj. \& Fulgosi-Masnjak, R. (1991): AAMD Adaptive Behavior Scale. Manual. Faculty of Defectology, University of Zagreb.

Guillén Martín, V.M., Adam Alcocer, A.L., Verdugo Alonso, M.Á., Giné, C. (2017). Comparison between the Spanish and Catalan versions of the Supports Intensity Scale for Children (SIS-C). Psicothema, 29, 126-132. doi: 10.7334/psicothema2016.200

Hagiwara, M., Shogren, K. A., \& Shaw, L. A. (2019). Examining the impact of respondent-level factors on scores on the Supports Intensity Scale-Children's Version. American Journal on Intellectual Developmental Disabilities, 124, 309-323. doi: 10.1352/1944-7558-124.4.309 سلس

Kimmich, M., Agosta, J., Fortune, J., Smith, D., Melda, K., Auerbach, K., \& Taub, S. (2009). Developing individual budgets and reimbursement levels using the supports intensity scale. ILRU Program.

Luckasson, R., Borthwick-Duffy, S., Buntix, W. H.E., Coulter, D. L., Craig, E. M., Reeve, A., . . Tassé, M. J. (2002). Mental retardation: Definition, classification, and systems of supports (10th ed.). American Association On Mental Retardation.

Luckasson, R., Coulter, D., Polloway, E., Reiss, S., Schalock, R., Snell, M, \& Stark, J. A. (1992). Mental retardation: Definition, classification and systems of supports. American Association on Mental Retardation.

Mason, A., \& Goddard, M. (2009). Payment by results in mental health: A review of the international literature and economic assessment of the Integrated Packages Approach to Care (InPAC). Centre for Health Economics. الس الس الس الس

Mueller, R. O. (1996). Basic principles of structural equation modeling: An introduction to LISREL and EQS. Springer-Verlag.

Nihara, K, Foster, R., Shellhaas, M., \& Leland, H. (1969). Adaptive Behavior Scales, manual. American Association on Mental Deficiency.

Nunnely, J. \& Bernstein, I. (1994). Psychometric theory. McGrawHill.

Salvador-Carulla, L., Reed, G. M., Vaez-Azizi, L. M., Cooper, S.-A., Martinez-Leal, R., Bertelli, M., ... Saxena, S. (2011). Intellectual developmental disorders: towards a new name, definition and framework for "mental retardation/intellectual disability" in ICD-11. World Psychiatry: Official Journal of the World Psychiatric Association (WPA), 10, 175-80. doi: 10.1002/j.2051-5545.2011. tb00045.x الئلس

Schalock, R. S., Thompson, J. R., Tassé, M. (2008). Resource allocation and the Supports Intensity Scale: Four papres on issues and approaches. American Association on Intellectual and Developmental Disabilities. الس الس الس الس

Schalock, R. L., Borthwick-Duffy, S. A., Bradley, V. J., Buntinx, W. H. E, Coulter, D., Craig, E. M. \& Yeager, M.H. (2010). Intellectual disability: Definition, classification, and systems of supports (11th ed.). American Association on Intellectual and Developmental Disabilities.

Seo H., Shaw L. A., Shogren K. A., Lang K. M., \& Little T. D. (2016). The benefits of latent variable modeling to develop norms for a translated version of a standardized scale. International Journal Of Behavioral Development, 46, 743-750. doi: 10.1177/0165025416671612

Shogren, K. A., Seo, H., Wehmeyer, M., Hughes, C., Thompson, J.,Little, T., \& Palmer, S. (2015). Support needs of children with intellectual and developmental disabilities: Age-related implications for assessment. Psychology in the Schools, 52, 874-891. doi: 10.1002/pits.21863 المالسلسلة

Shogren, K. A., Wehmeyer, M. L., Seo, H., Thompson, J. R., Schalock, R. L., Hughes, C., ... Palmer, S. B. (2017). Examining the reliability and validity of the Supports Intensity ScaleChildren's Version in children with autism and intellectual disability. Focus on Autism and Other Developmental Disabilities, 32, 293-304. doi: 10.1177/1088357615625060 الس السلبل

Smith, G., \& Fortune, J. (2008). The Supports Intensity Scale and resource allocation. In: J. R. Schalock, J. R. Thompson, \& M. J. Tassé (Eds.), Resource allocation and the Supports Intensity Scale: Four papers on issues and approaches (pp. 3-6). American Association on Intellectual and Developmental Disabilities

Snell, M., Luckasson, R., Borthwick-Duffy, S., Bradley, V., Buntix, W., Coulter, D., ... Yeager, M. (2009). Characteristics and needs of people with intellectual disability who have higher IQs. Intellectual and Developmental Disabilities, 47, 220-233. doi:

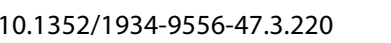

Sram, Z. (2014). Exploratory and confirmatory factor analysis of the Nationalist Syndrome Scale (sns-1). Political Perspectives, 4, 7-30. Wلس

Tassé, M. J., \& Thompson, J. R. (2010). Supports Intensity Scale for Children translation guidelines. Paper presented at the 134th Meeting of the American Association on Intellectualand Developmental Disabilities, Providence, RI.

Thompson J, Wehmeyer, M. L., Hughes, C, Shogren, K. A., Palmer, B. S., \& Seo, H. (2014). The Supports Intensity Scale-Children's Version: Preliminary reliability and validity. Inclusion, 2, 140149. doi: 10.1352/2326-6988-2.2.140 لسلسلس

Thompson, J. R., Bradley, V. J., Buntinx, W. H. E., Schalock, 
R. L., Shogren, K. A., Snell, M. E., . . Yeager, M. H. (2009). Conceptualizing supports and the support needs of people with intellectual disability. Intellectual and Developmental Disabilities, 47, 135-146. doi: 10.1352/1934-9556-47.2.135 سلسلس

Thompson, J. R., Bryant, B. R., Campbell, E. M., Craig, E. M., Hughes, C. M., Rotholz, D. A., ... Wehmeyer, M. (2004). Supports Intensity Scale: User's manual. American Association on Mental Retardation.

Thompson, J. R., Wehmeyer, M. L., Hughes, C., Shogren, K. A., Seo, H., Little, T. D., . . Tassé, M. J. (2016). Supports Intensity Scale-Children's Version: User's manual. American Association on Intellectualand Developmental Disabilities.

Thompson, J. E., \& Wehmeyer, M. L. (2008). Historical and legal issues in developmental dis- abilities. In H. P. Parette \& G. R. Peterson- Karlan (Eds.), Research based practices in develop- mental disabilities (2nd ed., pp. 13-42). ProEd.

Van Loon, J. (2009). Using the Supports Intensity Scale in practice. Resource allocation and planning individual supports based on the Supports Intensity Scale. Siglo Cero, 40, 54-66.

Verdugo, M.A., Guillén, V.M., Arias, B., Vicente, E., \& Badia, M. (2016). Confirmatory factor analysis of the Supports Intensity Scale for children. Research in Developmental Disabilities, 49-50, 140-152. doi: 10.1016/j.ridd.2015.11.022 سلسلس

Weiss, J. A., Lunsky, Y., Tassé , M. J., \& Durbin, J. (2009). Support for the construct validity of the Supports Intensity Scale based on clinician rankings of need. Research in Developmental Disabilities, 30, 933-941. doi: 10.1016/j.ridd.2009.01.007 سلس الس الس World Health Organization. (2001). International classification of functioning, disability and health: ICF. World Health Organization.

RECEIVED 02.10.2019| ACCEPTED 03.03.2020 